\title{
Post-traumatic stress disorder after subsequent birth to a gestational loss: An observational study
}

\author{
Eloísa Fernández Ordóñez, ${ }^{\prime}$ Cristóbal Rengel Díaz, ${ }^{2,3}$ Isabel María Morales Gil, ${ }^{3}$ María Teresa Labajos Manzanares ${ }^{4}$
}

Hospital de la Serranía de Ronda, Málaga, España.

2 Hospital Universitario Virgen de la Victoria, Málaga, España.

3 Departamento de Enfermería, Universidad de Málaga, Málaga, España.

${ }^{4}$ Departamento de Fisioterapia, Universidad de Málaga, Málaga, España.

\section{Correspondence:}

Eloísa Fernández Ordóñez

C/ Arquitecto Francisco Peñalosa, 3,

29071, Málaga, España.

Phone: 951952801

Email: eloisafdezordonez@gmail.com

Received: 23 January 2020

Accepted: 31 March 2020

Citation:

Fernández Ordóñez, E., Rengel Díaz, C., Morales Gil, I. M., \& Labajos Manzanares, M. T. (2020). Post-traumatic stress disorder after subsequent birth to a gestational loss: An observational study. Salud Mental, 43(3), 129-136

DOI: $10.17711 /$ SM. $0185-3325.2020 .018$

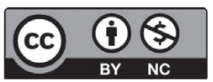

\begin{abstract}
Introduction. The loss of a pregnancy puts women at risk of suffering post-traumatic stress disorder. This circumstance can influence a subsequent pregnancy, and the link with the future baby. Objective. The main objective of this work was to identify the prevalence of post-traumatic stress disorder (PTSD) among post-partum women who give birth after having suffered a previous gestational loss and to identify possible relationships between PTSD and the variables studied. Method. An observational, descriptive, and cross-sectional study. A total of 115 puerperal women who had suffered a previous gestational loss completed questionnaires containing sociodemographic variables, obstetric history, and responses to the Davidson Trauma Scale. Results. A score of 40 was established as a cut-off point in the Davidson Trauma Scale for the identification of PTSD. $21.7 \%$ of the participants scored 40 or above. Significant differences were found related to age $(p=.030)$, number of pregnancies $(p=.033)$, and number of gestational losses $(p=.001)$. The probability of PTSD increases significantly in relation to the number of losses. Respondents are 2.55 times ( $\beta=.94 p=.027$ ) more likely to suffer PTSD the higher the number of gestational losses suffered. Discussion and conclusion. There are significant differences in the presence of PTSD among puerperal women in terms of age, number of pregnancies, and number of gestational losses. Post-partum women are more likely to suffer PTSD after a gestational loss the higher the number of gestational losses suffered.
\end{abstract}

Keywords: Mental health, perinatal loss, grief, pregnancy, post-traumatic stress disorders.

\section{RESUMEN}

Introducción. La pérdida de un embarazo sitúa a las mujeres en riesgo de padecer un trastorno por estrés postraumático. Esta circunstancia puede influir en un embarazo posterior, y el vínculo con el futuro bebé. Objetivo. El objetivo principal de este trabajo fue identificar la prevalencia de trastorno por estrés postraumático entre puérperas que dan a luz tras haber sufrido una pérdida gestacional previa e identificar posibles relaciones entre el trastorno por estrés postraumático y las variables estudiadas. Método. Se trata de un estudio observacional, descriptivo y transversal. Un total de 115 puérperas que habían sufrido una pérdida gestacional anterior llenaron cuestionarios que contenían variables sociodemográficas, de la historia obstétrica y la Escala de Trauma de Davidson. Resultados. Se estableció 40 como punto de corte en la Escala de Trauma de Davidson para identificar el trastorno por estrés postraumático. Se identificó en un $21.7 \%$ de las participantes. Se encontraron diferencias significativas relacionadas con la edad $(p=.030)$, el número de embarazos $(p=.033)$ y el número de pérdidas gestacionales $(p=.001)$. La probabilidad de trastorno por estrés postraumático aumenta significativamente en relación con el número de pérdidas. Es 2.55 veces $(\beta=.94 p=.027)$ más probable padecer un trastorno por estrés postraumático cuanto mayor sea el número de pérdidas gestacionales sufridas. Discusión y conclusión. Existen diferencias significativas en la prevalencia de trastorno por estrés postraumático entre las puérperas en cuanto a la edad, el número de embarazos y el número de pérdidas gestacionales. Es más probable padecer trastorno por estrés postraumático tras una gestación posterior a una pérdida gestacional cuanto mayor sea el número de pérdidas gestacionales sufridas.

Palabras clave: Salud mental, pérdida perinatal, duelo, gestación, trastorno por estrés postraumático. 


\section{INTRODUCTION}

Post-traumatic stress disorder (PTSD) is defined by the DSM-5 (2013) as the change of the body's response to a stressful circumstance. The presence of one or more intrusion signs associated with the traumatic event are described as symptoms: memories, dreams or dissociative reactions related to the traumatic event, psychological distress or intense physiological reactions when exposed to circumstances reminiscent of the traumatic event.

The DSM-IV (2000), with respect to its previous version, is more explicit and restrictive regarding the experience of traumatic events, limiting medical incidents considered traumatic to those involving sudden and catastrophic events. Whereas in the DSM-V, PTSD is no longer included in anxiety disorders but in a new category called "Trauma-related disorders and stressful events."

Since 1987, PTSD figures have been recorded in the general population with values ranging from $.5 \%$ to $10.8 \%$ in men and between $1.3 \%$ and $18.3 \%$ in women. The prevalence of current PTSD is $3.5 \%$ in the general population and rises in populations with high rates of exposure to traumatic events (Rojas Campos, 2016).

Among the risk factors for suffering PTSD are being female (women are twice as likely to develop PTSD), history of mental health problems, the perception of vital risk during trauma, perception of little support after trauma, and the presence of physical sequelae and high levels of psychosocial stress. Other risk factors include low socioeconomic and educational level. A third of people suffering from PTSD lives with symptoms ten years later (Figueroa, Cortés, Accatino, \& Sorensen, 2016).

PTSD is diagnosed in up to $25 \%$ of pregnant women who suffer a gestational loss a month after the traumatic event (Engelhard, van den Hout, \& Arntz, 2001). These authors identified the relationship between the duration of pregnancy and the severity of PTSD, especially with the re-experiencing of symptoms. As a pregnancy progresses, the loss becomes more tangible, which can provide sustenance for intrusive memories. This study draws attention to the fact that the loss of a pregnancy, regardless of gestational age, in addition to producing depression, places women at risk of PTSD.

These figures contrast with the prevalence of PTSD in pregnant women who have not suffered a previous gestational loss ranging from $4 \%$ to $6 \%$ (Yildiz, Ayers, \& Phillips, 2017).

Turton, Hughes, Evans, \& Fainman (2001) identified a lifetime risk of $29 \%$ for PTSD following a gestational loss and a prevalence of up to $21 \%$ of PTSD symptoms during the third trimester of a pregnancy after a fetal death.

Even a year after the birth of a healthy baby after a prior gestational loss, prevalence rates ranging from $4 \%$ to $6 \%$ were reported. Armstrong, Hutti, \& Myers (2009) explored anxiety and post-traumatic stress depression levels in 36 couples during the third trimester of pregnancy, and again at three and eight months post delivery and found that depressive, anxiety, and post-traumatic stress symptoms decreased significantly over time.

In addition, they found a significant correlation between depression, post-traumatic stress, and anxiety. In a later study (Hutti, Armstrong, Myers, \& Hall, 2015), they related the greater intensity of grief with higher levels of post-traumatic stress and more intrusive thoughts, images, and nightmares.

Complicated perinatal grief can be a significant predictor of post-traumatic stress (Krosch \& Shakespeare-Finch, 2017).

It is necessary to pay attention to the differences among the kinds of perinatal losses depending on whether they are voluntary or not. It is what Boltansky defined as the difference between "tumor fetus," the accidental embryo not called to become the object of a life project, and a "fetus project", whom the parents welcome as a new being (Boltanski, 2016).

The consequences of untreated PTSD in the perinatal period can cause maternal depression, poor prenatal care, prematurity, risky behaviors, excessive weight gain, breastfeeding problems, lack of attachment, etc. (Vignato, Georges, Bush, \& Connelly, 2017).

The findings of the study by Cook, Ayers, \& Horsch (2018) suggest that post-partum PTSD is associated with low birth weight and lower rates of breastfeeding. An estimated up to $25 \%$ of pregnancies conclude with a perinatal loss, and between $50-86 \%$ of women who suffer a perinatal loss will conceive again (Cordle \& Prettyman, 1994; Cuisinier, Kuijpers, Hoogduin, de Graauw, \& Janssen, 1993). This means that pregnancy after a perinatal loss is a very common situation in the clinical practice of obstetrics. However, in most cases there is no specific attention for these women and their families. PTSD has been related to pathologies such as anxiety and depression (Armstrong et al., 2009). The possible implication of these disorders for the mental health of the mother and the well-being of her child includes examining how such cases might be better managed in clinical situations.

The main objective of this work was to identify the prevalence of PTSD among puerperal women who give birth after having a previous gestational loss and to identify possible relationships between PTSD and the sociodemographic and obstetric variables studied.

\section{METHOD}

\section{Study design}

This is an observational, cross-sectional study of a descriptive and inferential nature. 


\section{Description of the sample}

This is the study of a set of variables at a given time in order to describe them and establish possible relationships between them. There has been no manipulation of the variables by the researchers. The source of information is described through a questionnaire.

The descriptive variables to be studied are divided between sociodemographic variables (age), socio-educational variables (educational level), and variables of obstetric history (type of gestational loss, week of gestation in which the loss occurred, number of pregnancies, number of pregnancy losses, number of children prior to pregnancy loss, family history of pregnancy loss, and time elapsed between pregnancy loss and subsequent pregnancy). The outcome variable is the Davidson Trauma Scale rating.

\section{Procedure}

As an inclusion criteria, women 18 and over who had given birth in one of the public hospitals of the province of Malaga, having previously suffered a gestational loss, were eligible for inclusion in the study. Among the previous gestational losses were spontaneous abortions, voluntary interruptions, interruptions due to fetal anomalies, and fetal deaths. Regarding the exclusion criteria, women who were pregnant and those who did not have mastery in Spanish (the language of the questionnaire) were excluded. Consecutive sampling was carried out. The data was collected in September, 2018. A total of 115 women completed questionnaires. The demographic characteristics and the obstetric history of the participants are presented in Table 1.

The data was collected in an ad hoc fashion. Data points included age, level of education, family history of gestational loss, number of pregnancies, number of gestational losses suffered, number of live children, type of gestational loss, week of gestation in which the gestational loss occurred, and the time elapsed between the loss and the subsequent pregnancy. The Davidson Trauma Scale designed by Davidson et al., 1997 and adapted to Spanish by (Annex; Bobes et al., 2000) was used to assess the frequency and severity of PTSD symptoms in subjects who had suffered a stressful event. Items are based on DSM-IV criteria and consist of 17 items. Those referring to intrusion and avoidance make reference to the stressful event, while those of dullness, isolation, and hyperactivation only value the presence or absence of them. Each item is evaluated through two subscales: one of frequency and severity. The frequency scale offers five possible answers (never, sometimes, 2-3 times, 4-6 times, daily) that score from 0 to 4 . The gravity scale also presents five possible answers (nothing, mild, moderate, marked, extreme), which are scored in the same way as the previous scale. The authors propose the most efficient 40-point cutoff, which offers a sensitivity of $69 \%$, a specificity of $95 \%$, a positive predictive value of $92 \%$, and a negative predictive value of $83 \%$. Regarding its psychometric properties, the Davidson's Trauma Scale obtained a test-retest reliability after two weeks of .86. The internal consistency, both for the frequency and severity subscales and for the total, is high (Cronbach's alpha of .97 - .98 - .99, respectively). In the Spanish validation, the Cronbach's alpha obtained was .9 (Bobes et al., 2000).

The data collection for this research was carried out through the delivery of informative booklets and the collection of data from those women who fulfilled the inclusion criteria and chose to participate in the study. The study took place in the five public hospitals in the province of Malaga (Spain), having an obstetrics service. Prior to conducting the study, permissions were sought from those responsible for the direction of the different hospitals in which the data collection would be carried out. Once receiving permission from agency ethics committees, data was collected. The field work took place between the months of May 2017 and October 2018. Possible participants were identified at the time of admission during the preparation of the anamnesis. The obstetric formula recorded in the Pregnant Women's Health Document reflects perinatal losses prior to the current pregnancy. During the immediate puerperium (within the first week after delivery) women who met the inclusion criteria were verbally informed of the object of the study. Upon their willingness to participate, they received a booklet consisting of an information sheet, informed consent form, socio-

Table 1

Demographic and obstetrical data

\begin{tabular}{lrrrrr}
\hline & $N$ & Minimum & Maximun & \multicolumn{1}{c}{$M$} & \multicolumn{1}{c}{$S D$} \\
\hline Age & 115 & 18 & 46 & 32.16 & 5.947 \\
Number of pregnancies & 115 & 2 & 7 & 3.07 & 1.212 \\
Number of gestational losses & 115 & 1 & 5 & 1.53 & .862 \\
Week of gestational loss & 115 & 4 & 40 & 10.64 & 5.579 \\
Number of children & 115 & 0 & 4 & .51 & .765 \\
Time elapsed & 115 & 1 & 240 & 28.88 & 43.724 \\
Total score PTSD & 115 & 0 & 116 & 28.19 & 24.847 \\
N valid (per list) & 115 & & & & \\
\hline
\end{tabular}


demographic, and obstetric data, Perinatal Behavior Scale, and Davidson Trauma Scale. The participants answered each of the items of the questionnaire individually and without a limit of time. To determine the prevalence of post-traumatic stress disorder, scores greater than 40 on the Davidson Trauma Scale were established as the cut-off point.

\section{Statistical analysis}

Descriptive statistics were performed by exploratory analysis and frequency distribution, as well as determination of the normality of variables by the Kolmogorov-Smirnov test and analysis of asymmetry, kurtosis, and histograms. A bivariate analysis was carried out using Student's t test and Wilcoxon according to the normality of the distributions to evaluate the differences between continuous variables due to the voluntary nature of the losses and to evaluate the relation of appearance of PTSD with maternal age, number of pregnancies, number of previous perinatal losses, week of gestation in which the loss occurred, number of live children before the loss, and time elapsed between the perinatal loss and the attainment of the subsequent pregnancy. A Chi square test was also performed to determine the relationship between the qualitative variables of the study. Finally, multivariate logistic regression models were constructed to assess factors associated with the occurrence of perinatal grief and post-traumatic stress. The Hosmer-Lemeshow adjustment statistic and the correct classification capacity were calculated. Post-hoc power analyses were also performed to identify possible type II errors in the differences found in the bivariate analysis of post-traumatic stress with age, the number of pregnancies, the number of perinatal losses, the week of the loss, the number of children, and the time elapsed between the loss and the subsequent pregnancy. All analyses were carried out with the software SPSS 25, GPower and Epidat 4.1 (Table 2).

\section{Ethical considerations}

This work has the favorable reports of the Ethics Committee of Experimentation of the University of Malaga (CEUMA) and the Portal of Ethics of Biomedical Research of Andalusia (PEIBA). The project was carried out according to the rules of Good Clinical Practice and the provisions of the Declaration of Helsinki and the available evidence regarding attention to gestational or perinatal loss. During the implementation of this project, the anonymity of the participants was maintained under Organic Law 15/1999 of December 13, on the protection of personal data in order not to violate the rights of the participants and protect their privacy and confidentiality.

\section{RESULTS}

A total of 115 women, aged 18 to 46, answered the questionnaires. Regarding their educational attainment, the highest percentage of the participants, 34.8\%, had secondary education, $22.6 \%$ of them had completed vocational studies, $26.1 \%$ had university studies while a $16.5 \%$ only had primary studies.

Regarding the week of gestation in which the previous perinatal loss occurred, the range varied from 4 to 40 weeks of gestation, the mean being 10.64 (DT $=5.579)$, so that most losses $(85.2 \%)$ occurred before the 12 th week of pregnancy. Losses until the 20th week of gestation raised the total to $93.9 \%$. Losses above the 30th week represented $1.8 \%$ of the data.

The most frequent cause of perinatal loss was abortion, with $70.4 \%$ of cases. Voluntary interruptions accounted for $20 \%$, interruptions for malformations, $7 \%$, while fetal deaths were only $2.6 \%$ of the total.

The determination of PTSD is defined by a score of 40 higher in the Davidson Trauma Scale. The prevalence of PTSD in our sample is $21.7 \%$ of the participants.

Considering the possible differences in the prevalence of PTSD in different types of gestational losses, the following results were obtained: among women who had suffered a spontaneous abortion, 19.8\% had PTSD. Among women who requested a voluntary termination of pregnancy, $17.4 \%$ of women showed PTSD. Among women who decided to interrupt their pregnancies because of fetal abnormalities, $37.5 \%$ exhibited PTSD. Among the participants who suf-

Table 2

Logistic regression model to identify risk of post-traumatic stress, adjusted for age, loss, number of pregnancies and number of losses

\begin{tabular}{lrrrrr}
\hline & & & & \multicolumn{2}{c}{ IC 95\% OR } \\
\cline { 5 - 7 } & \multicolumn{1}{c}{$B$} & Sig. & OR & Lower & Higher \\
\hline Age & .06 & .228 & 1.06 & .96 & 1.16 \\
Voluntariness of the loss & .47 & .390 & 1.61 & .55 & 4.74 \\
Number of pregnancies & -.12 & .702 & .89 & .48 & 1.63 \\
Number of gestational loss & .94 & .027 & 2.55 & 1.11 & 5.85 \\
\hline
\end{tabular}

Notes: Hosmer-Lemeshow: chi $=9.12, p=.334$; correct classification capacity: $80.9 \%$. 
fered the fetal death of the child who was expected, $66.7 \%$ presented PTSD. The possible differences in the prevalence of PTSD according to the highest level of formal education completed were evaluated. Among women who had completed only primary education, 26.3\% showed PTSD; among participants who had completed secondary education, $15 \%$; among those who had studied vocational training, 23.1\%; and among those who had completed university studies, $26.7 \%$. In the bivariate analysis, Student's t test and Wilcoxon were performed according to the normality of the distributions, to evaluate differences between continuous variables due to the voluntariness of the losses and to evaluate the relation of the PTSD appearance.

In this analysis, the following data were obtained: the average age in the group of women who show evidence of PTSD is more than three points higher than in those that do not. As for the average number of pregnancies, it is also more than half a point higher in the group that presents PTSD. Likewise, the average number of losses is almost one point higher among the group of women in whom PTSD is observed. The mean of the week of pregnancy in which the loss occurred is two points higher in the group of women suffering from PTSD, although with a fairly high dispersion $(S D=8.969)$. Regarding the time elapsed from the gestational loss to the subsequent pregnancy, it is lower by more than eight points in the group that presents PTSD. As shown in Table 3 , age $(p=.030)$, the number of pregnancies $(p=.033)$ and the number of gestational losses $(p$ $=.001$ ) are statistically signficant. The probability of post-traumatic stress disorder increases significantly in relation to the number of losses. A subject is 2.55 times $(\beta=.94 p=.027)$ more likely to suffer PTSD as the number of gestational losses suffered increases. The number of gestational losses suffered is presented as an independent predictor.

\section{DISCUSSION AND CONCLUSION}

The number of subjects who evince PTSD in the sample studied is $21.7 \%$. These results coincide with those of the study conducted by Turton et al. (2001).
There are no differences in the type of gestational loss and the presence of PTSD. These results differ from those obtained by the review of Daugirdaite, van den Akker, and Purewal (2015), which conclude that the gestational loss of an unplanned pregnancy is related to the development of PTSD, both in men and women, although in men it is associated with a higher gestational age. In this case, PTSD is related to feelings of guilt. There are also no differences in the level of education completed by the subject and the presence of PTSD. There are differences, although not statistically significant, in terms of the week of gestation in which the loss occurred and in the time elapsed from the gestational loss to the subsequent pregnancy. Similar results obtained the review carried out by Daugirdaite et al. (2015) who found that the duration of gestational age is associated with a higher probability of diagnosing PTSD and with the results of Turton et al. (2001), who found a higher risk of suffering PTSD during pregnancy when this ocurred shortly after a gestational loss.

These results can be explained by the fact that the older the gestational age, the more invasive the techniques used in the finalization of the pregnancy, whether it is voluntary or not. Furthermore, when gestational losses occur earlier in a pregnancy, the possibility of viewing the fetus is not usually offered to the prospective parents. However, at a higher gestational age, this option is often requested by the parents themselves. Turton et al. (2001) warn of the increased risk of PTSD when parents are encouraged to observe and hold the deceased baby.

Regarding the issue of time elapsed, Yehuda and McFarlane (1995) show that in most cases the symptoms of PTSD resolve 2-3 years after the traumatic event. Hughes, Turton, and Evans (1999) argue that half of the women who suffer a gestational loss will conceive again within 12 months. A subsequent pregnancy may function as a stressor, reactivating the experience and putting the woman in a vulnerable situation to suffer PTSD (Turton et al., 2001). DeBackere, Hill, and Kavanaugh (2008) observed an increase in the presence of post-traumatic stress disorder when there was a short period of time between the loss and a subse-

Table 3

Presence of post-traumatic stress

\begin{tabular}{lcccc}
\hline & Negative & Positive & & \\
& $M(S D)$ & $M(S D)$ & & \\
& $n=90$ & $n=25$ & $p$ & $1-\beta$ \\
\hline Age & $31.49(5.99)$ & $34.56(5.23)$ & .030 & .95 \\
Number of pregnancies & $2.9(1.01)$ & $3.68(1.65)$ & .033 & .95 \\
Number of gestational losses & $1.37(.63)$ & $2.12(1.27)$ & .001 & .95 \\
Week of gestational loss & $10.02(4.05)$ & $12.88(8.97)$ & .580 & .95 \\
Number of children & $.51(.71)$ & $.52(.96)$ & .564 & .95 \\
Time elapsed & $30.76(47.83)$ & $22.12(23.12)$ & .397 & .95 \\
\hline
\end{tabular}


quent pregnancy. On the other hand, there are significant differences in the number of pregnancies and the number of gestational losses. The number of gestational losses significantly increases the risk of suffering PTSD. These results coincide with those of Giannandrea, Cerulli, Anson, and Chaudron (2013) who found that women with multiple losses were more likely to be diagnosed with major depression and/or post-traumatic stress disorder than women with a history of a single gestational loss.

The present study is innovative when it comes to evaluating the symptoms of PTSD after a gestation which ends successfully among women who have suffered a gestational loss. Another of its strengths is broadening the typology of gestational losses to include both voluntary and involuntary losses and at different moments of gestation. The fact that the data collection was carried out during the first week of the puerperium minimizes the possible concomitant symptoms of puerperal depression. In addition, advanced statistical and control techniques have been included.

However, there are a number of limitations. The main one is determined by the sample size. Likewise, the small number of participants limits the generalizability of results and conclusions. It would be desirable to have a larger number of participants. Additionally, it is important to highlight the cultural diversity of the women who give birth in the hospital centers of the province of Malaga. This study did not take into account the cultural differences of the puerperal women that may influence the development of symptoms of perinatal grief or post-traumatic stress disorder. For example, the linguistic barrier reduced the number of possible participants to those women who were able to read in Spanish. Also, voluntary participation may have eliminated women with more severe PTSD symptoms. The observational design of the study does not allow us to establish a causality between the different related factors. A longitudinal design could satisfy the achievement of said objective. Another important limitation is not having had access to the socioeconomic data of the participants, as well as the kinship relationships. From a gender perspective, it would be interesting to obtain the results of the women's partners who have participated in the study. On the other hand, qualitative research methods could approach the experience of pregnancy after gestational loss in a more comprehensive way.

There are significant differences in the presence of PTSD among puerperal women in terms of their ages, number of pregnancies, and number of gestational losses. One is more likely to suffer PTSD after a successful gestation following a number of gestational losses. The reluctance of many women to participate in the study, as well as that of other health professionals to collaborate in the collection of data, shows that gestational losses continue to be a complicated issue to address, both for people who experience it and for the professionals who care for them. However, women who have suffered such losses should be evaluated by health professionals during pregnancy and the puerperium to identify anxiety, depression, and dissociative tendencies, since in these cases they are more likely to develop PTSD (Haagen, Moerbeek, Olde, van der Hart, \& Kleber, 2015). For his part, Christiansen (2017) states that PTSD continues to be poorly recognized after a perinatal loss and, consequently, its symptoms are treated as symptoms of grief. This is problematic since these two entities do not share the same protective factors or the same risk factors, and they do not in parallel. Occasionally, the symptoms of PTSD appear in the course of a subsequent pregnancy and $4 \%$ of women develop chronic PTSD. These data should be taken into account by reproductive health professionals who care for early gestational losses and still tend to consider them as insignificant events (Engelhard et al., 2001). Erroneously, professionals may consider that the effects of a gestational loss are resolved after a pregnancy that ends successfully; however, the symptoms can be reactivated and endure, affecting the health of the mother and the child.

\section{Funding}

None.

\section{Conflicts of interest}

The authors declare they have no conflicts of interest.

\section{REFERENCES}

American Psychiatric Association (2000). Diagnostic and Statistical Manual of Mental Disorders (4th ed., text revision). Washington, DC: American Psychiatric Association.

American Psychiatric Association (2013). Diagnostic and Statistical Manual of Mental Disorders (5th ed.) Washington, DC: American Psychiatric Association.

Armstrong, D. S., Hutti, M. H., \& Myers, J. (2009). The Influence of Prior Perinatal Loss on Parents' Psychological Distress After the Birth of a Subsequent Healthy Infant. Journal of Obstetric, Gynecologic \& Neonatal Nursing, 38(6), 654-666. doi: 10.1111/j.1552-6909.2009.01069.x

Bobes, J., Calcedo-Barba, A., García, M., François, M., Rico-Villademoros, F., González, M. P., \& Bousoño, M. (2000). Evaluación de las propiedades psicométricas de la versión española de cinco cuestionarios para la evaluación del Trastorno de Estrés Postraumático. Actas Españolas de Psiquiatría, 28(4), 207-218.

Boltanski, L. (2016). La condición fetal: una sociología del engendramiento y del aborto. Madrid: Akal.

Christiansen, D. M. (2017). Posttraumatic stress disorder in parents following infantdeath: A systematic review. Clinical Psychology Review, 51, 60-74. doi:10.1016/j.cpr.2016.10.007

Cook, N., Ayers, S., \& Horsch, A. (2018). Maternal posttraumatic stress disorder during the perinatal period and child outcomes: A systematic review. Journal of Affective Disorders, 225, 18-31. doi: 10.1016/j.jad.2017.07.045

Cordle, C. J., \& Prettyman, R. J. (1994). A 2-year follow-up of women who have experienced early miscarriage. Journal of Reproductive and Infant Psychology, 12(1), 37-43. doi: 10.1080/02646839408408866

Cuisinier, M. C. J., Kuijpers, J. C., Hoogduin, C. A. L., de Graauw, C. P. H. M., \& Janssen, H. J. E. M. (1993). Miscarriage and stillbirth : time since the loss, grief intensity andsatisfaction with care. European Journal of Obstetric \& Gynecology and Reproductive Biology, 52(3), 163-168. doi: 10.1016/00282243(93)90066-L

Daugirdaite, V., van den Akker, O., \& Purewal, S. (2015). Posttraumatic Stress and Posttraumatic Stress Disorder after Termination of Pregnancy and 
Reproductive Loss: A Systematic Review. Journal of Pregnancy, 1-14. doi: $10.1155 / 2015 / 646345$

Davidson, J. R., Book, S. W., Colket, J. T., Tupler, L. A., Roth, S., David, D., ... Feldman, M. E. (1997). Assessment of a new self-rating scale for post-traumatic stress disorder. Psychological medicine, 27(1), 153-160. doi: 10.1017/ S0033291796004229

DeBackere, K. J., Hill, P. D., \& Kavanaugh, K. L. (2008). The Parental Experience of Pregnancy After Perinatal Loss. Journal of Obstetric, Gynecologic \& Neonatal Nursing, 37(5), 525-537. doi: 10.1111/j.1552-6909.2008.00275.x

Engelhard, I. M., van den Hout, M. A., \& Arntz, A. (2001). Posttraumatic stress disorder after pregnancy loss. General Hospital Psychiatry, 23(2), 62-66. doi: 10.1016/S0163-8343(01)00124-4

Figueroa, R. A., Cortés, P. F., Accatino, L., \& Sorensen, R. (2016). Trauma psicológico en la atención primaria: orientaciones de manejo. Revista médica de Chile, 144(5), 643-655. doi: 10.4067/s0034-98872016000500013

Giannandrea, S. A. M., Cerulli, C., Anson, E., \& Chaudron, L. H. (2013). Increased Risk for Postpartum Psychiatric Disorders Among Women with Past Pregnancy Loss. Journal of Women's Health, 22(9), 760-768. doi: 10.1089/jwh.2012.4011

Haagen, J. F. G., Moerbeek, M., Olde, E., van der Hart, O., \& Kleber, R. J. (2015). PTSD after childbirth : A predictive ethological model for symptom development. Journal of Affective Disorders, 185, 135-143. doi:10.1016/j. jad.2015.06.049

Hughes, P. M., Turton, P., \& Evans, C. D. H. (1999). Stillbirth as risk factor for depression and anxiety in the subsequent pregnancy: Cohort study. British Medical Journal, 318(7200), 1721-1724. doi: 10.1136/bmj.318.7200.1721
Hutti, M. H., Armstrong, D. S., Myers, J. A., \& Hall, L. A. (2015). Grief Intensity, Psychological Well-Being, and the Intimate Partner Relationship in the Subsequent Pregnancy after a Perinatal Loss. Journal of Obstetric, Gynecologic \& Neonatal Nursing, 44(1), 42-50. doi: 10.1111/1552-6909.12539

Krosch, D. J., \& Shakespeare-Finch, J. (2017). Grief, traumatic stress, and posttraumatic growth in women who have experienced pregnancy loss. Psychological Trauma: Theory, Research, Practice, and Policy, 9(4), 425-433. doi: $10.1037 / \operatorname{tra} 0000183$

Rojas Campos, M. (2016). Trastorno de Estrés Postraumático. Revista Médica de Costa Rica y Centroamérica, 73(619), 233-240. Retrieved from https://www. medigraphic.com/pdfs/revmedcoscen/rmc-2016/rmc162h.pdf

Turton, P., Hughes, P., Evans, C. D. H., \& Fainman, D. (2001). Incidence, correlates and predictors of post-traumatic stress disorder in the pregnancy after stillbirth. British Journal of Psychiatry, 178(6), 556-560. doi: 10.1192/bjp.178.6.556

Vignato, J., Georges, J. M., Bush, R. A., \& Connelly, C. D. (2017). Post-traumatic stress disorder in the perinatal period: A concept analysis. Journal of Clinical Nursing, 26(23-24), 3859-3868. doi: 10.1111/jocn.13800

Yehuda, R., \& McFarlane, A. C. (1995). Conflict between current knowledge about posttraumatic stress disorder and its original conceptual basis. American Journal of Psychiatry, 152(12), 1705-1713. doi:10.1176/ajp.152.12.1705

Yildiz, P. D., Ayers, S., \& Phillips, L. (2017). The prevalence of posttraumatic stress disorder in pregnancy and after birth: A systematic review and meta-analysis. Journal of Affective Disorders, 208, 634-645. doi: 10.1016/j.jad.2016.10.009 
ANNEX

Davidson's Trauma Scale

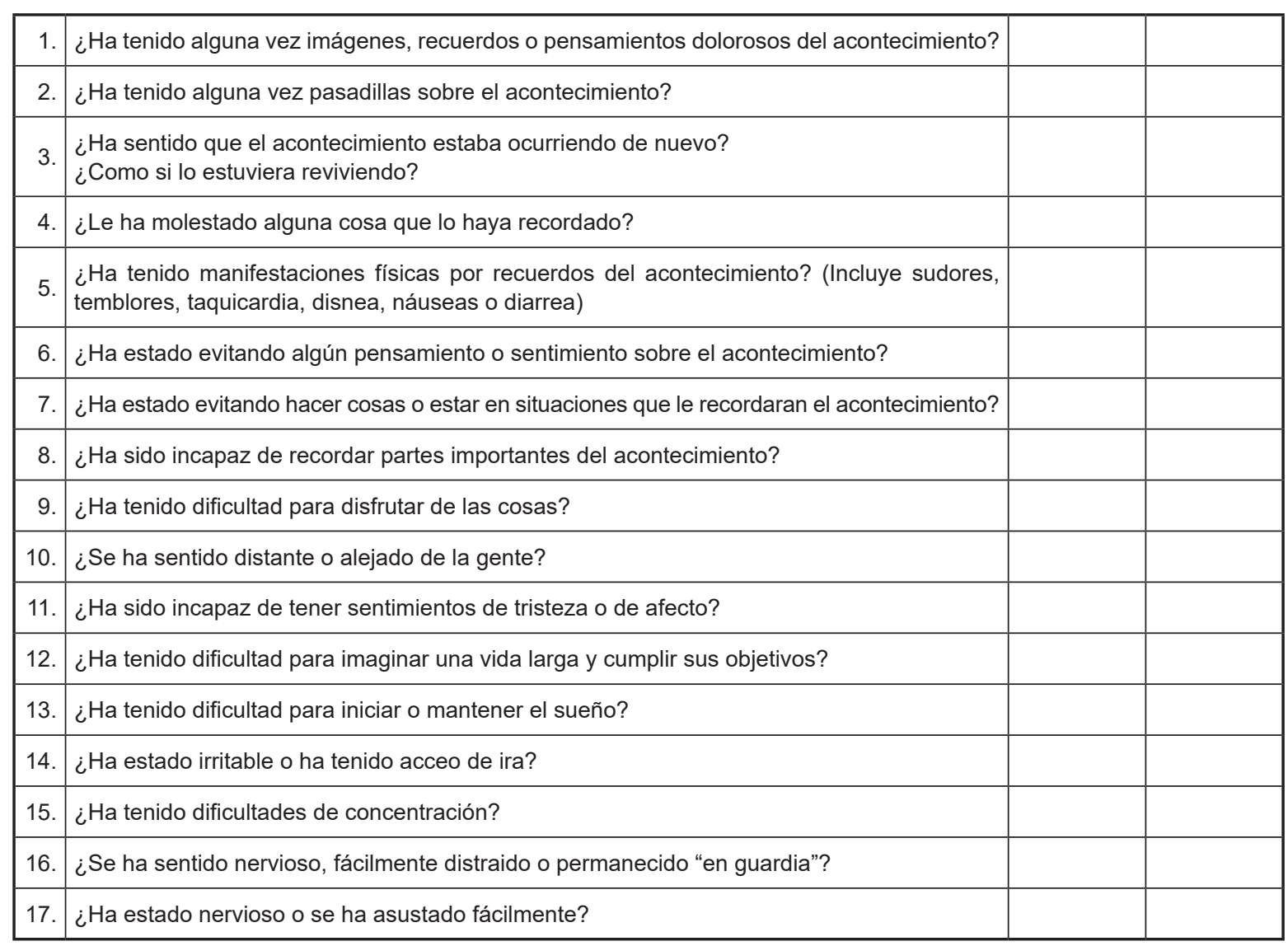

